مجلة كلية التربية الرياضية - جامعة بغداد * المجلا الثامن والعثرون ** العدد الرابع * لسنة

تأثيز تمريناث للقوة الوظفية في تطوير بعض قدرات العضلاث العاملة في رياضة الجمناستثا الفزي للاعبين الثشباباب

\title{
فريال يونس نومان
}

أ.د. صالح مجيد العزاوي

مستخلص البحث باللغة العربية.

هدفت الدراسة الى اعداد تمرينات للقوة الوظيفية في تطوير بعض قدرات العضلات العاملة فضلا عن التعرف على تأثثر التمرينات الوظيفية في بعض قدرات العضلات العاملة ثم شرح لمفهوم القوة الوظيفية اضافة الى العضلات العاملة واستخدمت الباحث المنهج التجريبي لتحقيق اهداف الدراسة كما اشتملت عينة البحث على ستة لاعبين من المنتخ الوطني للاعبين الثباب في الجناستك وقامت الباحثة بإجراء ثناث تجارب استطلاعية وتجربة رئيسية للتعرف على طريقة عمل جهاز الاككترومايوكراف (EMG) ومسافة المُستقبّل الذي يمكن النقاط الاشتارة بلوتوث وعرضها في الحاسوب المحمول وخزنها من خلال برنامج myo research وقامت الباحثة وفريق العمل المساعد تجديد اجراءات تحضير موقع الاقطاب على الجلد فوق العضلة وتثبيت الاسلاك وكان المجال الزماني لتنفيذ التجارب من 2016/7/20 ولغاية 2015/11/25.

كما وقامت الباحثة بعرض وتحليل ومناقثة النتائج للاختبارات القبلية والبعدية لجميع المتغيرات اذ تمت العلمية الخاصة بموضوع البحث.

واخيرا توصلت الباحثة الى بعض الاستنتاجات منها • ان تدريبات القوة الوظيفية ساعدت على نظوير القوة العضلية القصوى لدى اللاعبين الثباب بالجمناستك الفني.

كما اوصت الباحثة بعدة توصيات منها: • قوة الاعتماد على التمرينات المعدة للقوة الوظيفية عند تدريب اللاعبين الثباب • ينبغي تجهيز قاعات التدريب بالمستلزمات الخاصة بتدريبات القوة الوظيفية لما تحققه من مردود ايجاد في التطور البدني والمهاري. 
مجلة كلية التربية الرياضية - جامعة بغداد * المجلا الثامن والعثرون * العدد الرابع ** لسنة

\section{Abstract}

\section{The effect of Functional Strength Exercises on the Development of Some}

\section{Working Muscles in Youth Artistic Gymnastics for Men}

The aim of the research was to design functional strength exercise to develop some working muscles capacities as well as identifying the effects of functional strength exercises on working muscles. The researchers used the experimental method and the subjects were (6) youth gymnasts. The researchers conducted three pilot studies using EMG to catch Bluetooth signals to display them on a laptop and save them on Myo research program. The researchers conducted the experiments from 20/7/2016 - 25/11/2015. The data was collected and treated using proper statistical operations to come up with the results. The researchers concluded that functional strength exercises develop maximum muscular strength in youth gymnasts. The researcher recommended depending on functional strength exercises when training youth gymnasts and equipping training gyms with functional strength equipments due to their positive effect in developing physical and skillful performance.

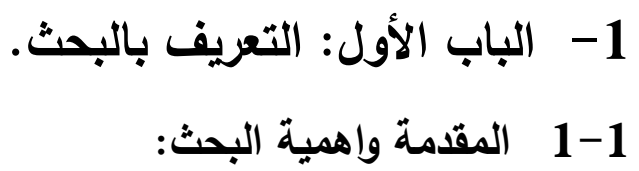

يعتمد علم التدريب الرياضي على طرق عديدة حيث تختلف كل رياضة في طريقة تدريبها عن الاخرى طبقا

لطبيعة الاداء ونظام الطاقة الملائم والذي في ضوئها يعمل المدرب على نطويرها والارتقاء بمستوى الاداء الرياضي للوصول الى الهدف المراد تحقيقه.

وكل منابع لتطوير المستويات الرياضية في العالم يدرك ان للتدريب الرياضي شأن عظيم في اعداد وصيانة وتطوير القدرات الانسانية بأبعادها المختلفة من اجل تفجير اقصى ما بمكنه من قدرات بداخل الانسان من طاقات في اتجاه الهدف المنشود ومن هذا المنطلق يمكن النظر الى التنريب الرياضي على انه عملية يتم فيها تطوير واستخدام اساليب ووسائل تدريبية مختلفة بهدف تغير حالة المتنرب وفقا لهدف تم تحديده مسبقا.

لقد وضع علماء التدريب الرياضي عنصر القوة في قمة هرم القدرات البدنية لكونها من اهم القدرات اذ نعد

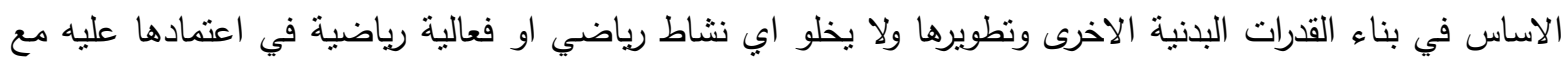
ملاحظة النباين في اهية هذا العنصر من فعالية الى اخرى وحسب منطلبات الواجب الحركي. 
مجلة كلية التربية الرياضية - جامعة بغداد * المجلا الثامن والعثرون * العدد الرابع * لسنة

ان المناهج التدريبية المدعمة بتقويم الاختبارات البدنية والوظيفية نسهم في اعطاء فكرة مستقبلية عن

التأثنرات الانعكاسية لتلك الجوانب لمدى اللاعبين وبالتالي على الصفات البدنية المختلفة.

واذ ان رياضة الجمناستلك الفني للرجال احدى الالعاب التي تنتلزم تكامل بالقدرات البدنية والحركية لكونها

$$
\text { من الفعاليات الثناثية الحركية والتي تتصف بدمج الحركات المركبة والصعبة معاً. }
$$

اذ تبرز الحاجة الى كفاءة وظيفية عالية عن طريق الاعداد البدني والمهاري ومن هنا برزت اهمية البحث

في دراسة تأثثر تمرينات للقوة الوظيفية في بعض قدرات العضلات العاملة لنطوير اداء المنطلبات الخاصة على جهاز الحلق للاعبين الثباب اذ ظهر مفهوم جديد في تدريبات القوة وهو تدريب القوة الوظيفية بوجود اجزة متنوعة تعمل على تحسين القوة وتقوية عضلات المركز الني تعتبر منشأ الحركة.

2-1

يتطلب التدريب على المهارات في الجمناستك الفني للرجال قدراً كبيرا من القوة القصوى في كل مجموعة من

المجاميع العضلية للاعب وكلما ارتفع مستوى القوة القصوى أصبح من السهل أداء الحركات الصعبة ومن خلال خبرة الباحثة كونها تدريسية في الكلية ومتابعتها لنتائج لاعبي المنتخب الوطني وجدت ان هناك ضعف واضح في اداء حركات القوة التي لها علاقة بالمتطلبات الخاصة لأجهزة الجمناستك مما يؤدي الى كثرة السقوط من وعلى الاجهزة لذلك سعت الباحثة الى وضع تمرينات للقوة الوظيفية من اجل رفع مستوى اللاعبين من حيث الجوانب المهارية والبدنية للاعبين الثباب

\section{3-1 الهداف البحث:}

1. اعداد تمرينات للقوة الوظيفية في بعض قدرات العضلات العاملة في رياضة الجمناستك الفني للاعبي المنتخب. 2. التعرف على تأثثر تمرينات القوة الوظيفية في تطوير بعض قدرات العضلات العاملة في رياضة الجمناستك

$$
\text { الفني للاعبي المنتخب الوطني. }
$$

\section{1-4 رضيات البحث:}

1. لا توجد فروق ذات دلالة إحصائية بين الاختبارات القبلية والبعدية في بعض القدرات العضلات العاملة. 2. هناك تباين في نسب التطور لبعض قدرات العضلات العاملة.

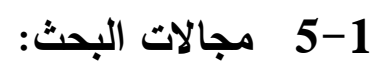

1. المجال البشري: لاعبوا المنتخب الوطني العراقي للجمناستك.

2. المجال الزماني: من 2015/8/5 ولغاية 2015/11/5.

3. المجال المكاني: قاعة الثهيد سمير خماس للجمناستك. 
مجلة كلية التربية الرياضية - جامعة بغداد * المجلا الثامن والعثرون * العدد الرابع ** لسنة

1-6 ت تحديد المصطلحات: • القوة الوظيفية: functional Strength training: هي مزيج من تدريبات القوة وتدريبات التوازن يؤديان في توقيت واحد. (79:1) ( ت ن

2- 2- الباب الثاني: الدراسات النظرية وإلسابقة: 1-2 1-1-2 1-2

العضلات هي الجزء الفاعل من الجهاز الحركي وهي تعمل وفق التعليمات التي تصلها عبر الاعصاب وتتكل العضلات حوالي 40 الى 50 \% من وزن الجسم ، ويحتوي الجسم على 600 عضلة تكون ما يعرف باللحم وعند انقباض تللك العضلات فأنها نؤثر في حركة الجسم بكل اجزاءه.

كما تؤنز ايضا تلك العضلات في الكثير من العمليات الحيوية الاخرى منل حركة الدورة الدموية وتتفس وغيرها.

والعضلات مثل سائر اعضاء الجسم المختلفة تتكون من خلايا الى انها خلايا من نوع خاص فهي طويلة ورفيعة ومن المعتاد تجمع عدد كبير منها لتكوين وحدة العضلة والتي تسمى الليفة العضلية ومن اغرب صفات الالياف العضلية قدرتها على انقباض او القصر او الانبساط. (:44:2) في جسم الإنسان عضلات مخططة يبلغ عددها 320 زوجاً من العضلات المخططة الإرادية أي 640 عضلة مفردة، العدد الفعلي يتراوح بين 640 و 850 عضلة باعتبار أن النبان بعض أجزاء العضلات يمكن اعتبارها عضلات مستقلة

تقسم العضلات حسب الناحية النشريحية إلى عدة فئات: عضلات الرأس، عضلات العنق، عضلات

$$
\text { الأطراف العليا، عضلات الجذع وعضلات الأطراف السفلى. (33:10) }
$$

\section{2-1-2 2 انواع العضلات في جسم الانسان:}

تتولى العضلات المسؤولية عن حركة مختلف اجزاء الجسم بسبب قابليتها على التقلص. وتتشأ العضلات

من طبقة الميزوديرم في الجنين وتتكون من خلايا منطاولة تدعى بالألياف العضلية وكمية قليلة من المادة البينية. توجد في جدران القناة الهضمية وجدران الممرات التتفسية وجدران الاوعية الدموية وتوجد ايضاً في الجلا وفي اقسام اخرى من جسم الانسان، ان تقلص هذه العضلات لا يكون تحت سيطرة ارادة الفرد ولهذا سميت باللاإرادية، تتألف العضلة الملساء من خلايا طويلة مغزلية الثكل تظهر مستديرة او مضلعة في المقطع العرضين، كل خلية تحتوي على نواة بيضوية او قضيبية مركزية الموقع، يظهر الساينوبلازم تحت المجهر الاكتروني والذي يدعى بالسايتوبلازم 
مجلة كلية التربية الرياضية - جامعة بغداد * المجلا الثامن والعثرون * العدد الرابع * لسنة

العضلي محتوياً على حزم من الخيوط العضلية. تمنل هذه الحزم اللييفات العضلية تحت المجهر الضوئي. تكون هذه الحزم موازية للمحور الطولي للخلية وغير مخططة عرضياً.

يظهر الغشاء البلازمي للخلية العضلية الملساء تحت المجر الالكتروني محاطاً بغشاء قاعدي ترافقه الياف شبكية. يتجمع السايتوبلازم العضلي حول وعند قطبي النواة حيث يحتوي على المحتويات الحية للخلية كالمايتوكوندريا وجهاز كولجي والثبكة الاندوبلازمية الحاوية على الراييوسومات. نوجد الالياف العضلية الملساء مفردة او بشكل حزم او صفائح وتترتب الخلايا او الالياف بشكل منتظم تقريباً حيث ويظهر الجزء الوسطي المتوسع لليف الواحد مقابلاً للجزء المستدق النهائي للألياف الاخرى المجاورة ولهذا نظهر النواة في بعض الالياف في المقطع العرضي ولا نظهر في بعضها الاخر .

\section{2-1-2 3 القوة العضلية:}

تُعد القوة العضلية صفة من أهم الصفات البدنية على الإطلاق، فهي: "محدد هام في تحقيق التفوق الرياضي لمعظم الأنشطة الرياضية، حيث نسهم في إنجاز أي نوع من أنواع أداء الجهد البدني، ولكن تتفاوت نسبة مساهنها تبعاً لنوع الأداء، لذلك فهي نتغل حيزاً كبيراً في برامج التدريب الرياضي. (125:19)

وهناك علاقة مهمة بين القوة العضلية والحركة، فهي المؤثر الذي تتتج عنه الحركة والعامل الأساس لإنتاج

هذه الحركة التي يسنطيع الفرد بها من تحريك نفسه أو تحريك جهاز أو أداة أو أي مقاومة خارجية. (265:4)

ويشير كل من (حسين وبسطويسي) أيضاً أن أهمية القوة العضلية نكمن في ارتباطها بالأداء المهاري أو

الفني لبعض الفعاليات الرياضية كرفع الأثقال وفعاليات الرمي والوثب والعدو القصير بألعاب القوى، وبخاصة أوجه القوة الانفجارية والقوة المميزة بالسرعة. (19:5)

تعد القوة العضلية واحدة من الصفات البدنبة الضرورية والمهمة في الألعاب والمهارات الحركية والتي يتأسس عليها الإنجاز ومنطلباته، وهي تعني المقدرة او التوتز الذي تستطيع عضلة او مجموعة عضلية ان تتتجها ضده مقاومة في أقصى انقباض إرادي واحد لها، وللقوة العضلية أهمية: (167:18)

1. تنهم في إنجاز أي نوع من أنواع أداء الجهد البدني في كافة الرياضات وتتفاوت نسبة مساهمتها طبقا للأداء. 2. تسهم في تقدير العناصر والصفات البدنية الأخرى منل السرعة والتحمل. 3. تعتبر مصدرا هاما في تحقيق التقوق الرياضي في معظم الرياضات.

والقوة العضلية الخاصة تهف الى تتمية مقدار القوة العضلية للعضلات التي تعمل بشكل أساسي في الرياضة التخصيصية للفرد، وتستخدم تمريناتها في مدة الأعداد العام والخاص من المنهاج التدريبي كما أنها تعمل 


\section{مجلة كلية التربية الرياضية - جامعة بغداد ** المجلد الثامن والعشرون ** العدد الرابع ** لسنة}

على تتمية أنواع القوة العضلية طبقا لنسب مساهمتها في الأداء التخصصي، وتؤهل العضلات بشكل رئيس في الأداء الحركي للرياضة الممارسة لتمرينات المنافسة. (150:19)

وقد عرفت القوة العضلية بعدد من التعاريف من قبل المختصين والباحثين في مجال التدريب الرياضي، وعرف (أمر اله احمد) القوة العضلية بأنها "مقدرة اللاعب في التغلب على مقاومات مختلفة ومواجنها، وهي من أهم مكونات اللياقة البدنية"(89:2) وكذلك عرفها (أبو العلا احمد واحمد نصر الدين) بانها: "قدرة الجهاز العصبي في التغلب على مقاومة لأطول فترة ممكنة".(84:1) وعرف (صادق فرج) القوة العضلية بأنها "القوة هي متغير إنجازي حركي ذات طبيعة فسيولوجية تؤثر في تكوينها ومسنوى إنجازها الكثير من المتغيرات العضلية والعصبية"(8:8)، أما مفتي إبراهيم حماد فيعرفها بأنها "المقدرة او التوتر التي تنتطيع عضلة او مجموعة عضلية أن تتتجها ضد مقاومة في أقصى انقباض إرادي واحد لها". (127:18) وذكر (محمد رضا) "إن تحسين القوة العضلية قد أدى الى تحسين مستوى الانجاز بما يعادل (8 - 12) مرة مقارنة مع الرياضيين الذين يستخدمون المهارات الفنية فقط في تحقيق الانجازات لألعاب رياضية معينة". (615:19)

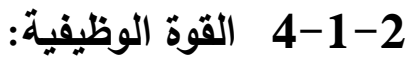

الوظيفة: هو الفعل الذي يوجد عند الثخص او الثيء ويكون مناسبا له. (11:5) وتعرف تدريبات القوة الوظيفية" هي مزيج من تدريبات القوة وتدريبات التوازن يؤديا في نوقيت واحد".

(134:6)، ويشير ديف شميتز (2003) إلى أن التدريبات الوظيفية تتميز بخصائص وسمات من أهمها: (98:7)

1. التركيز على مجموعة عضلات المركز: فجميع الحركات الرياضية ستقتقر للكفاءة بدون تكاملها مع عضلات قوية

للمركز ، فعضلات المركز القوية نساعد على ربط الطرف السفلى بالطرف العلوي، بالإضافة إلى منع تسرب القوة. 2. تعدد المستويات: أداء الحركات الرياضية في أكثر من اتجاه وعدم قصر التمرين على اتجاه واحد فقط، فالجسم البشرى مصمم ولدية القدرة على التحرك مباثرة للأكام ولليسار ولليمين وأيضا التدوير، والتدريب يجب أن يعمل على تحسين هذه القدرات من خلال التركيز على الأبعاد الثناثة للحرك (الأفقي - السهمي - الرأسي). 3. تعدد المفاصل: يلاحظ عند الثقاط شيء من الأرض تحرك عدد كبير من المفاصل، فالتدريب يجب أن يركز على استعمال أكثر من مفصل بدلا من مفصل واحد، فطلوع الدرج يعتبر أكثر تأثثرا من رفع ثقل بالرجلين، كما أن اللاعب يقضى كثيرا من الوقت ضد ثأثثرات الجاذبية الأرضية، لذا يجب التركيز على عضلات التثبيت الرئيسية الموجودة في المركز . 4. السيطرة على التوازن المضاد: الحركات متعددة الاتجاهات تتطلب نوازن، وهنا لا بتطلب فقط عضلات قوية للمركز، بل مهارة كافية وتوافق للأداء، ويتم ممارسة التدريبات الدينامية للتوازن مع أو بدون حد أقصى للتوازن المضاد، وتعمل تتمية التوازن على تحسين شكل الأداء والإحساس بالقوة المنتجة. 
مجلة كلية التربية الرياضية - جامعة بغداد * المجلا الثامن والعثرون * العدد الرابع * لسنة

5. طرف واحد: معظم المهارات الرياضية يتطلب أدائها التزكيز على ساق واحدة، وحتى في حياتتا العادية نؤدي مهامنا المختلفة باستخدام يد واحدة، ومن هنا لزم التركيز على طرف واحد.

6. الأطراف المتناوية: الجري والمشي يؤديا عن طريق انتقال أقدامنا في أسلوب تنادلي، والتدريب بهذا الأسلوب يعمل على تحسين الحركات الطبيعية والقوة العامة والتوافق في الأداء.

7. الحركة التكاملية: الرفع والمشي والجري جميعها حركات تؤدى من قبل مفاصل وعضلات متعددة تعمل سويا كنتيجة لاتصالهم المثالي ببعضهم، لذا يجب أن يهذف التدريب الوظيفي إلى زيادة حساسية الجسم وتكامله.

8. النشاط النوعي: ويتطلب لتحقيق ذلك فهم طبيعة ومتطلبات النشاط الرياضي المؤدى، فلاعب الجمباز يختلف أسلوب تدريبة عن لاعب الماراثون أو لاعب كرة القدم، ومن خلال فهم متطلبات الأداء نحدد التمارين والمقاومات لتلبية تلك الاحتباجات.

9. السرعة النوعية: لتحقيق سرعة الأداء يجب أن يكون التدريب سريعا، ولتحقيق التحكم والثبات يجب أن يكون

$$
\text { التدريب بطيئا. }
$$

ويرى (2011) Louise) إلى أن البرامج الوظيفية تتكون من ثلاث عناصر رئيسية هي: (47:8)

1. ثبات المركز: وهي حركات تؤدى بتكرارات قليلة، وشدة بسيطة أو متوسطة مع التقدم التدريجي في الأداء وتهدف إلى

$$
\text { تحقيق الثبات الذاتي والتحكم العصبي العضلي في عضلات المركز . }
$$

2. قوة المركز : وهي حركات ذات دينامية أكثر ، وتستخدم مقاومات خارجية في جميع المستويات الحركية وتهف إلى تحقيق القوة العضلية والتكامل الحركي. 3. قدرة المركز: وهي عبارة عن حركات تتميز بإنتاج قوة وتحويلها إلى سرعة فورية. مما تقدم فأن تدريب القوة الوظيفية يتعلق بالأساس البدني الذي يعمل على دعم جوانب الاداء المهاري بشكل خاص، اي بمعنى آخر يمكن تعريف القوة الوظيفية هي القوة المستخدمة والمحدة في اداء المهارات الفنية في الفعاليات الرياضية كل حسب نوعها.

أن تدريب القوة الوظيفية يعطي الرياضي القدرة في التحكم بالقوة بفعالية وكفاءة ودقة، وهنا فأن المهارة

الحركية تكون مهمة في تحقيق التفوق. (24:1) 2-1-2 يعرف الجمناستك بانه ذلك النشاط الذي يمارس على الاجهزة او على الارض بصورة فردية طبقا لقوانين متعارف عليها. 
مجلة كلية التربية الرياضية - جامعة بغداد * المجلا الثامن والعثرون * العدد الرابع ** لسنة

ان طبيعة نللك الرياضة من حيث تعدد اجهزتها ومهاراتها الحركية واختلافها من حيث مستويات الصعوبة والاداء الفني فضلا عن المنطلبات البدنية كل ذلك يجعل من الضروري ان يتدرب لاعب الجمناستك لساعات طويلة فقد ذكرت مصادر الاتحاد الدولي للجمناستلك ان الوصول الى مستويات متقدمة في الجمناستك يحتاج الى ست سنوات من التدريب الثاق والمستمر للإناث وحوالي نسع سنوات للذكور وهذا الفرق يعود الى الاختلافات بين الجنسين في هذه الاعمار والى منطلبات القوة العضلية لدى الذكور خاصة.

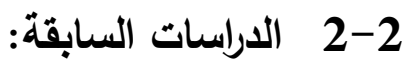
دراسة نعت كريم مصطفى(2012): (2012:16) دراسة نعمت كريم مصطفى (تأثير تدريبات القوة الوظيفية في تطوير بعض القدرات البدنية والهدف بكرة اليد

وكانت اهمية البحث في استخدام نوع من التدريبات الحديثة لتطوير القوة العضلية وهي القوة الوظيفية.

وقد هدفت الدراسة الى اعداد منهج تدريبي للقوة الوظيفية في تطوير بعض انواع التهديف لدى اللاعبين الثباب بكرة اليد وبرزت مشكلة البحث في ضعف القدرات البدنية والتي كانت السبب في عدم احراز اي تقدم في مستوى النتائج لبعض الأندية العراقية لكرة اليد.

وقد استخدمت الباحثة طريقة تدريبات القوة الوظيفية من خلال استخدام وسائل وادوات حديثه في التدريب منل الكرات الطبية والحبال المطاطية والدمبلصات

شملت عينه البحث عدد من لاعبي كرة اليد فئه الثباب لنادي الكرخ الرياضي بأعمار (16-18) سنة. ويعد تطبيق المنهج التدريبي ومعالجة تغيرات الدراسة احصائيا توصلت الباحثة الى ان هناك زياده معنويه في القوة العضلية القصوى اضافه الى بعض القدرات البدنية الاخرى.

\section{3- 3 الباب الثالث: منهجية البحث واجراء|ته الميدانية. \\ 1-3 منهجية البحث:}

نم استخدام المنهج التجريبي بتصميم المجموعة التجريبية الواحدة لملائمته تحقيق اهداف البحث ومحاولة التحكم في جميع المتغيرات. 
مجلة كلية التربية الرياضية - جامعة بغداد * المجلا الثامن والعثرون * العدد الرابع * لسنة

2-3

اختير مجتمع البحث بالطريقة العمدية" وهي عينة يتم اختيارها اختياراً حراً على اساس أنها تحقق أغراض

الدراسة التي يقوم بها الباحث" (84:21) وشملت العينة (6) لاعبين يمنلون كل مجتمع الاصل وعينته من المنتخب الوطني للجمناسنك.

1-2-3

من اجل حصول على تجانس بين افراد عينة البحث ولمنع المؤثرات التي قد تؤثثر على نتائج التجربة

من حيث الفروق الفردية الموجدة لدى اللاعبين في العمر والعمر التدريبي والطول والوزن قامت الباحثة بإيجاد معامل الالتواء للمتغيرات الاربعة، وقد دلت على ان جميع القياسات تحقق المنحى الاعتدالي والذي يوضح انها تتراوح ما بين (3+) مما يدل على تجانس افراد العينة والجدول ادناه يبين ذلك.

الجدول

يبين تجانس العينة في القياسات الانثرويومترية

\begin{tabular}{|c|c|c|c|c|c|}
\hline معامل الالتواء & الانحراف المعياري & الوسبط & الوسط الحسابي & وحدة القياس & المتغيرات \\
\hline 1.034 & 0.112 & 165 & 165.4 & 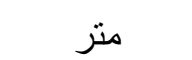 & الطول \\
\hline 2.066 & 4.658 & 59.000 & 60.800 & كغم & الكتلة \\
\hline 1.031 & 1.343 & 18 & 18.3 & سنة & العمر \\
\hline $0.548-$ & 0.548 & 9 & 9.3 & سنة & العمر التدريبي \\
\hline
\end{tabular}

يظهر الجدول (اعلاه) أن القيم معامل الالتواء تتحصر بين (3د) مما يدل على تجانس أفراد عينة البحث في هذه المتغيرات أي اعتدالية التوزيع الطبيعي لهم

3-3 وسائل جمع المعلومات والاجهزة والادوات المستخدمة في البحث:

1-3-3 وسائل جمع المعلومات:

• شبكة المعلومات الدولية (الانترنيت).

• المصادر العلمية المحلية والعربية والدولية (كتب، رسائل، الطاريح).

• المقابلات الثخصية للخبراء والمختصين بمجال اللعبة.

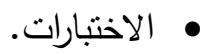

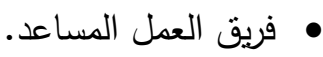

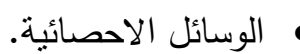


مجلة كلية التربية الرياضية - جامعة بغداد * المجلا الثامن والعشرون ** العدد الرابع ** لسنة

2-3-3 الاجهزة والادوات المستخدمة بالبحث:

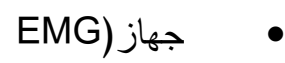

• ميزان لقياس الوزن عدد(1) صيني الصنع.

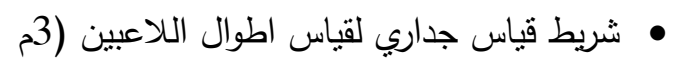

• • حبال كتان بطول (2م) عدد(4).

• حبال مطاط بطول(2) عدد(4).

• شرائط مطاط بطول(2م) عدد(4).

• مواد طبية مختلفة (شاش، معق،، لاصق جروح).

• ماكينات حلاقة استعمال واحد عدد (20).

• • ساعة توقيت يابانية الصنع عدد(1).

• سجل لنوثيق البيانات (100) ورقة عدد(1).

• كرات نوازن سويسرية الصنع عدد(2).

• • فوم رولر (رولة رغوية) عدد(2).

• بساط اسفنجي (2م3م) عدد(1).

• • جهاز حلق قانوني عدد(1).

• • مصطبة مخروطية عدد(1).

• مجموعة اثقال مختلفة الاوزان.

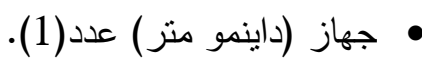

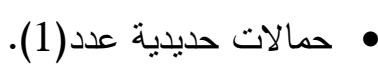

• كرات طبية عدد(2).

4-3

1-4-3 1-3 التجارب الاسنطلاعية:

قامت الباحثة بأجراء تجربتين استطلاعية على عينة من (2) من لاعبي المنتخب الوطني للجمناستك خارج

عينة البحث وعلى مدى يومين وكالاتي:

1-1-4-3 التجربة الاستطلاعية الاولى:

لاختبار صلاحية وعمل جهاز (Emg) وتمت يوم (2015/7/20) في تمام الساعة الرابعة عصراً. وكان

الغرض من هذه التجربة الاستطلاعية هي: 
مجلة كلية التربية الرياضية - جامعة بغداد * المجلا الثامن والعثرون * العدد الرابع * لسنة

التأكد من صلاحية عمل جهاز (Emg) وموضع تنتيت اقطاب الجهاز كونه ينطلب الدقة لقياس مؤشرات عمل العضلات.

حساب الوقت المستغرق للأداء.

ملاحظة مدى تجانس جهاز (Emg) مع عمل جهاز الحاسوب وتحديد كمية الذاكرة المسجلة لكل اداء. قياس وتحديد مسافة الكامرة الخاصة بجهاز (Emg) ومدى وضوح الاداء. مدى ملائمة قياسات الاربطة والحبال الموصولة بالأجهزة لقياسات اللاعبين.

3-1-4-3 التجرية الاستطلاعية الثانية: للاختبارات البدنية وإلمهارية:

تمت يوم (2015/7/21) الساعة الرابعة عصراً حيث تم التأكيد على:

تسجيل الزمن المستغرق لأداء الاختبارات البدنية.

$$
\text { مدى وضوح الاختبارات للاعبين. }
$$

مدى امكانية فريق العمل المساعد على تفهم وتوضيح الاختبارات للاعبين.

3-4-3 الاختبارات القبلية المستخدمة بالبحث:

1-2-4-3

قامت الباحثة بأجراء الاختبارات القبلية قبل البدء باستخدام المنهج التجريبي المعد من قبل الباحث وكان

اجراء هذه الاختبارات يوم 2015/7/25 على قاعة المركز التدريبي للجمناستك في مجمع المراكز التخصصية. اولاً: (اختبار البنج بريس): هو اختبار دفع البار الحديدي باليدين على مصطبة مستوية لدفع اقصى وزن للأعلى. (93:20)، وتكون مواصفات الاختبار كما جاءت في اغلب المصادر كالاتي: • الغرض من الاختبار : قياس القوة القصوى لعضلات الذراعين والكتفين في حركة الدفع إلى الأعلى. • الأدوات المستعملة: (مصطبة مستوية، بار حديدي، اقراص حديد مختلفة الاوزان).

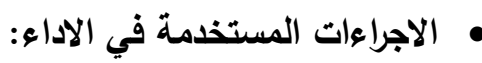

ل ع يتخذ المختبر وضع الرقود على الظهر فوق المقعد الحديدي.

ل ع يحمل المدرب البار الحديدي من الطرفين بحيث يحمل المختبر البار باليدين أمام الصدر . ل كون الذراعان مثثيتان وبأنساع الصدر تماما. • وصف الأداء:

عند إعطاء أثناره البدء يقوم المختبر بمد الذراعين لضغط البار الحديدي أمام الصدر حتى تصبح الذراعان

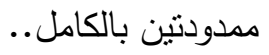
ل تقدير كمية التقل الحديدي وتسجيل البيانات في سجل البيانات. 
مجلة كلية التربية الرياضية - جامعة بغداد * المجلا الثامن والعثرون * العدد الرابع ** لسنة

ثانياً: اختبار القوة الثابتة لعضلات الظهر:

• الغرض من الاختبار: قياس قوة عضلات الظهر (الجذع) الباسطة (المادّة). • الأجهزة والأدوات: جهاز الدايناموميتز المنتبت على قاعدة خشبية.

• مواصفات الأداء: يقف المختبر على قاعدة الدايناموميتر حيث يقوم بثي الجذع قليلاً للأهام ممسكاً العارضة الحديدية بالقبضة المعكوسة (راحة إحدى اليدين للاخل والأخرى للخارج) وفي هذا الاختبار يجب تعديل طول السلسة الحديدية، ويراعى هنا أن تكون الرجلين ممدودة بكاملها، ويراعى ايضاً أن يكون الرأس والظهر للأمام مرفوعين. • طريقة التسجيل: تعطى إثنارة للمختبر بالثدّ للأعلى لإخراج أقصى قوة يستطيع ان يؤديها ومن خلال محاولتين، وتحتسب أدقّ وأفضل محاولة بـ (كغم).

3-4-3

اعتمدت الباحثة على التمرينات القوة الوظيفية التي اعدتها لتطبيقها في الوحدات التدريبية لعينة البحث في القسم الرئيس من الوحدات التدريبية لعينة البحث، وكانت مجموع الوحدات التدريبية (36) وحدة تدريبية ولمدة (ثلاثة اشهر) وكانت مدة تطبيق هذه التمارين داخل الوحدة التدربيية في نهاية القسم الرئيس (30 دقيقة) وطبقت (3) مرات في الاسبوع. انظر ملحق (1) الذي يبين المنهاج التدريبي والتمارين المستخدمة والذي اعدته الباحثة لنطبيق مفردات الوحدات التدربيية.

\section{4-4-3}

اجرت الباحثة اختباراتها البعدية البدنية في يوم الاحد الموافق 2015/11/22 بعد اكمال جميع الجرعات التدريبية التي تضمنت التمرينات المعدة من قبل الباحثة، وقد حاولت الباحثة اجراء هذه الاختبارات بنفس الظروف والاحوال التي جرت فيها الاختبارات القبلية، من خلال تثبيت جميع الظروف المتعلقة بالاختبارات من حيث الزمان والمكان والاجزة والادوات وطريقة التتفيذ من اجل العمل قدر الامكان على توفير نفس الظروف او قريباً منها عند اجراء الاختبارات

3-4-3 الوسائل الاحصائية:

$$
\begin{aligned}
& \text { 1. النسبة المئوية. } \\
& \text { 2. الوسط الحسابي. } \\
& \text { 3. الوسيط. } \\
& \text { 4. الانحراف المعياري. } \\
& \text { 5. معامل الالتواء. }
\end{aligned}
$$

6. قانون T.test للعينات غير المستقلة المترابطة. 
مجلة كلية التربية الرياضية - جامعة بغداد * المجلا الثامن والعثرون * العدد الرابع * لسنة

\section{4- الباب الرابع: عرض وتحليل ومناقشة نتائج البحث.}

4-1 عرض نتائج الأوساط الحسابية والانحرافات المعيارية وفرق الأوساط الحسابية (اختبار ت) في الاختبارات البدنية والنسبة المئوية للتظور بين نتائج الاختبارين القبلي والبعدي قيد البحث

\section{وتحليلها ومناقشتها:}

الجدول (التالي)

يبين الأوساط الحسابية والانحرافات المعيارية في الاختبارات البدنية قيد البحث في نتائج الاختبارين القبلي والبعدي

\begin{tabular}{|c|c|c|c|c|c|}
\hline \multicolumn{2}{|c|}{ الاختبار البعدي } & \multicolumn{2}{|c|}{ الاختبار القبلي } & \multirow{2}{*}{ وحدة } & \multirow{2}{*}{ الاختبارات } \\
\hline$\varepsilon$ & سنَ س & $\varepsilon$ & سَن س & & \\
\hline 7.746 & 60.000 & 6.124 & 52.500 & كغم & القوة القصوى للذراعين \\
\hline 15.492 & 100.000 & 10.368 & 87.500 & كغم & القوة القصوى لعضلات الجذع \\
\hline
\end{tabular}

من الجدول (اعلاه) يتبين:

• في اختبار القوة القصوى للذراعين: بلغ الوسط الحسابي في الاختبار القبلي (52.500) وبانحراف معياري مقداره (6.124)، في حين بلغ الوسط الحسابي في الاختبار البعدي (60.000) وبانحراف معياري مقداره (7.746). • في اختبار القوة القصوى لعضلات الجذع: بلغ الوسط الحسابي في الاختبار القبلي (87.500) وبانحراف معياري مقداره (10.368)، في حين بلغ الوسط الحسابي في الاختبار البعدي (100.00) وبانحراف معياري مقداره

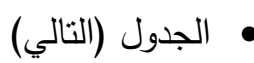

• يبين فرق الأوساط الحسابية وانحرافه المعياري وقيمة (t) المحسوبة ودلالة الفروق والنسبة المئوية للتطور بين نتائج

الاختبارين القبلي والبعدي في الاختبارات البدنية قيد البحث

\begin{tabular}{|c|c|c|c|c|c|c|c|}
\hline التطور \% نسبة & الفروق & مستوى الخطأ & المحسوية & ع ف & فَنَ & وحدة & المتغيرات \\
\hline 14.286 & معنوي & 0.001 & 6.708 & 2.739 & 7.500 & كغم & القوة القصوى للذراعين \\
\hline 14.286 & معنوي & 0.032 & 2.619 & 10.368 & 12.500 & كغم & القوة القصوى لعضلات الجذع \\
\hline
\end{tabular}

* درجة الحرية (6-1=5). معنوي عند مسنوى الخطأ (0.05) إذا كان مستوى الخطأ أصغر من (0.05) من الجدول (اعلاه) يتبين: (1) من

• في اختبار القوة القصوى للذراعين: بلغ فرق الأوساط الحسابية بين نتائج الاختبارين القبلي والبعدي (7.500) بانحراف معياري للفروق مقداره (2.739)، وبلغت قيمة (t) المحسوبة (6.708)، في حين كان مستوى الخطأ 
مجلة كلية التربية الرياضية - جامعة بغداد * المجلا الثامن والعثرون * العدد الرابع ** لسنة

(0.001)، مما يدل على معنوية الفروق بين الاختبارين القبلي والبعدي عند مستوى الخطأ (0.05) وأمام درجة حرية

(5) ولمصلحة الاختبار البعدي.

ه في اختبار القوة لعضلات الجذع: بلغ فرق الأوساط الحسابية بين نتائج الاختبارين القبلي والبعدي (12.500) بانحراف معياري للفروق مقداره (10.368)، وبلغت قيمة (t) المحسوبة (1.619)، في حين كان مستوى الخطأ (0.032)، مما يدل على معنوية الفروق بين الاختبارين القبلي والبعدي عند مستوى الخطأ (0.05) وأمام درجة حرية

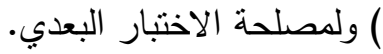

4-4 مناقثة نتائج اختبار فرق الأوساط الحسابية (اختبار ت) والنسبة المئوية للتطور بين نتائج

\section{الاختبارين القبلي والبعدي في الاختبارات البدنية قيد البحث.}

بعد الاطلاع على الجداول اعلاه وما تم عرضه وتحليله لنتائج الاختبارات البدنية قيد البحث، اتضح لنا بان متغيرات اختبار القوة القصوى للذراعين واختبار القوة القصوى لعضلات الجذع اظهر فرقاً معنوياً بين الاختبارين القبلي البعدي لمصلحة الاختبار البعدي وهو ما يؤكد الدور الايجابي لتمرينات المستخدمة خلال الوحدات التنريبية في القوة القصوى لعضلات الجذع اذ من خلال هذه التمرينات تعمل القوة العضلية لأب عضلة بشكل جماعي مع العضلات الأخرى اذ ان البنية الجسمية تعمل بشكل فعال معا من خلال تمرينات القوة الوظيفية التي تعني عمل الجسم بأجمعه معا في مسطحات الثناثة (امامي وجانبي والعرضي) ويتفق هذا مع ما أكده فابيو كومانا Fabio Cumana (ان تمرينات القوة الوظيفية عبارة عن حركات متكاملة ومتعددة المستويات (امامي، مستعرض، وسهمي) تتنتمل على تسارع والتنبيت والتباطؤ بهدف تحسين القدرة الحركية، القوة المركزية (يقصد بها العمود الفقري ومنتصف الجسم) والكفاءة العصبية والعضلية). (11:1) (2) (2) (11)

وتعزو الباحثة الى ان التمرينات القوة الوظيفية ايجابية من حيث ساهمت في اثرالك أكبر عدد من الالياف العضلية خلال التمرين الذي له دور فعال في اخراج القوة القصوى بأقصى حد ممكن. فالقوة القصوى تزداد كلما زاد عدد الالياف العضلية المشتركة في التمرين، وهذا كان أحد إيجابيات استخدام القوة الوظيفية ضمن المنهج التدريبي ولان القوة تعتمد على عدد الالياف المشتركة في العمل العضلي وهذا ما أكده العلماء "القوة القصوى تزداد في حالة القدرة على استثارة جميع الياف العضلة الواحدة او اثارة أكبر عدد من الياف العضلية الضرورية، فكلما زادت درجة شدة الحافز كلما تطلب ذلك مشاركة أكبر عدد من الالياف العضلية وزيادة القوة التي تسنطيع العضلة انتاجها". (167:15)

فضلا عن حدوث هذه التغيرات إلى التخطيط الجيد لبرنامج التمرينات الوظيفية وتقنين الأحمال التدريبية بأسلوب علمي مناسب للمرحلة السنية والتدريبية لعينة البحث وإلى استخدام الوسائل التدريبية الحديثة كجزء رئيسي في التدريبات الوظيفية بهدف تتمية القوة العضلية، حيث راعت الباحثة التدريب بأحمال متدرجة أثناء تطبيق البرنامج وذلك بتدريب المجموعات العضلية المختلفة وبخاصة عضلات المركز والذراعين وتركيز الباحثة على المجموعات العضلية 
مجلة كلية التربية الرياضية - جامعة بغداد * المجلا الثامن والعثرون * العدد الرابع * لسنة

العاملة خلال أداء حركات جهاز الحلق ودقة اختيار التمرينات الوظيفية حيث أدى ذلك إلى تحسين القوة القصوى لدى اللاعبين عينة البحث.

أما فيما يخص نسبه النطور فتعزو الباحثة ظهور الفروق المعنوية لمصلحة الاختبار البعدي ذلك الى

استخدام المنهج التدريبي المبني على أسس علمية الذي تم تطبيقه على اللاعبين أدى الى احداث تغيرات في مستوى

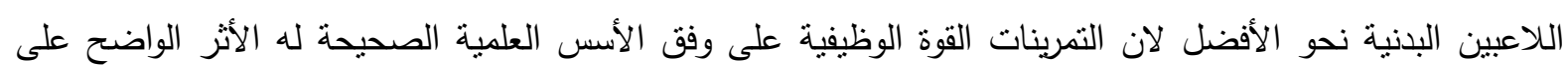
نتائج البعدية وهذا ما أكده أبو العلا احد (ان استخدام التدريبات التي تتفق في طبيعة أدائها مع الثكل العام لأداء المهارات التخصصية يؤدي الى نتائج أفضل في اكتساب القوة). (98:1) في اختبار القوة القصوى لعضلات الجذع: بلغ الوسط الحسابي في الاختبار القبلي (87.500) وبانحراف معياري مقاره (10.368)، في حين بلغ الوسط الحسابي في الاختبار البعدي (100.00) وبانحراف معياري مقداره (15.492)

\section{5- الباب الخامس: الاستنتاجات والتوصيات: 1-5}

ان تدريبات القوة الوظيفية ساعدت على تطوير القوة العضلية القصوى لاى اللاعبين الثباب بالجمناستلك الفني.

ان تدريبات القوة الوظيفية اظهرت فاعليتها من خلال عرض نتائج الاختبارات (القوة القصوى للذراعين) (القوة

$$
\text { القصوى لعضات الجذع). }
$$

استخدام تمارين القوة الوظيفية اشرك المجاميع العضلية بصورة ايجابية وساهم بأخراج القوة القصوى لاقصى حد

ممكن.

ان تقنين الاحمال التدريبية والتدرج بنطبيق المنهاج التدريبي ساهم في نسبة تطور الاداء للاعبين.

2-5

الاعتماد على التمرينات المعدة للقوة الوظيفية عند تدريب اللاعبين الثباب.

هنبغي تجهيز قاعات التدريب بالمستلزمات الخاصة بتدريبات القوة الوظيفية لما تحققه من مردود ايجاد في التطور

$$
\text { البدني والمهاري. }
$$

الاعتماد على الاختبارات الدورية الوظيفية لنقييم مدى نطور اللاعب.

عمل قاعدة بيانات سنوية لكل الفئات لاعتمادها في وضع المناهج التدريبية ومراعاة الفروق الفردية فيها. 


\section{مجلة كلية التربية الرياضية - جامعة بغداد * المجلد الثامن والعشرون * العدد الرابع * لسنة}

\section{المصادر العربية:}

1. أبو العلا احمد عبد الفتاح: التدريب الرياضي الأسس الفسيولوجية ، دار الفكر العربي ، القاهرة ، 1997. 2. امر الله احمد البساطي. التدريب البدنى الوظيفى في كرة القدم تخطيط وتدريب وقياس. دار الجامعة الجديدة

$$
\text { للنشر، الاسكندرية: } 2001 .
$$

3. احمد ابو العلا واحمد نصر الدين رضوان. فسيولوجيا اللباقة البدنية، القاهرة: دار الفكر العربي، 2003. 4. حسن، سليمان علي ولبيب، عواطف محمد:: تتمية القوة العضلية، ط3، دار الفكر المعاصر للنشر والتوزيع،

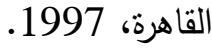

قاسم حسن واحمد، بسطويسي: التدريب العضلى الإيزوتونى في مجال الفعاليات الرياضية، ط1، دار الفكر

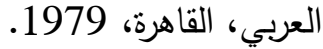

صريح عبد الكريم الفضلي: تطبيقات البيوميكانيك في التدريب الرياضي والأداء الحركى، ط2، جامعة بغداد، كلية

صائب العبيدي وعبد السلام عبد الرزاق؛ الأسس العلمية والتعليمية للحركات الجمناستيكية، مطبعة جامعة بغداد،

8. صادق فرج. مفاهيم حديثة للتكيف البدني، (نشرة تصدرها كلية التربية للبنات، جامعة بغداد)، 1999.

9. صمدي احمد، ياسر عبد العظيم، التنريب الرياضى أفكار ونظريات، القاهرة، جامعة الزقازيق 1999. 10. عبد الرحمن عبد الحميد زاهر : موسوعة فسيلوجيا الرياضة ، مركز الكتاب للنشر ، ط4، 2011. 11. عامر سكران حمزة، محمد محمود صالح: قانون الجمناستلك الفني، 2012. 12. عبد المقصود، السيد: نظريات التدريب الرياضى - تدريب وفسيولوجيا القوة، مركز الكتاب للنشر، القاهرة،

13. عادل عبد البصير، فوزي يعقوب رزق اله؛ النظريات والأسس العلمية في تدريب الجمباز (المنوازي - الحلق ـ

$$
\text { حصان الحلق، القاهرة: دار الفكر العربي. }
$$

14. عمرو صابر : تأثثر تدريبات القوة الوظيفية على كثافة المعادن والقدرة العضلية والتوازن ومستوى اداء مهارتي

الطعن والوثبة السهية لدى ناشئ المبارزة، بحث منشور، 2008. في مؤتمر الأولمبياد 2008 في القاهرة. 15. قاسم حسن حسين، ومنصور جميل العنبكي: اللياقة البدنية وطرق تحققها، بغداد، مطبعة التعليم العالي، 1988. 16. نعمت كريم مصطفى، تأثنر تدريبات القوة الوظيفية في تطوير بعض القدرات البدنية والتهديف بكرة اليد للشباب، رسالة ماجستير، الجامعة المستصرية، كلية التربية الأساسية (2012).

17. محد رضا إبراهيم. التطبيق الميداني لنظريات وطرق التدريب الرياضي، بغداد: دار الكتب والوثائق، 2008. 18. مفتي إبراهيم، التدريب الرياضى الحديث، دار الفكر العربي، القاهرة، 2001. 19. مفتي إبراهيم: التدريب الرياضى الحديث - تخطيط وتطبيق وقيادة، ط1، دار الفكر العربي، 1998. 


\section{مجلة كلية التربية الرياضية - جامعة بغداد ** المجلد الثامن والعثرون * العدد الرابع ** لسنة}

20. محمد حسن علاوي واحمد نصر الدين رضوان؛ اختبارات الادراك الحس حركي، ط 2، دار الفكر العربي،

$$
\text { 21. محمود عثمان ؛ قراءات في البحث العلمي، القاهرة، دار الفكر العربي، } 2001 .
$$$$
\text { المصادر الانكليزية }
$$

1. Fabio command (2004): function training for sports, Human Kinetics: Champaign IL, England.

2. Johnson, T.and Kluber. Skeletal Muscle following Tonic overload: Function and structure Analysis. (Medicine and science in sports and Exercise 32. (1985).

3. Welsh at el, E.A., M. Bird, and J.L. Mayhew: Electromyography activity of the pectorals major and anterior deltoid muscles during 3 upper-body lifts, (Journal strength and Conditioning Research. 19(2): 2005)

4. Raj Kumar, Vino: Biomechanics of Bench Press - Dumbbell Versus Barbell, (Health and fitness Exercise, No. 9, Nov. 2010).

5. Ingrid lose miller \& gimp hanker. Functional strength for triathletes. 2012

6. Matte Dixon ;physiologist for mere professional triathlete.2011.

7. Taffeta, D.R and Marcus. R. (2004): The muscle strength and bone dentist relationship in young women dependence on exercise status, journal of sports medicine and physical Fitness.

8. Yasumura ST, Hamamura A, Ishikawa M, Ito H, Ueda Y, Takehara M, Miyaoka H, Murai C, Murakami S, Moriyama M, Yamamoto K, Yoshinaga T, Takeuchi T.(2000)

9. Characteristics of functional training and effects on physical activities of daily living, Nippon Koshu Eisei Zasshi.

10. Fabio command (2004): function training for sports, Human Kinetics: Champaign IL, England.

11. Sheppard, J. M. \& Young, W. B. (2006): Agility literature review: Classifications, training and testing, Journal of Sports Sciences, September. 
مجلة كلية التربية الرياضية - جامعة بغداد * المجلا الثامن والعشرون * العدد الرابع * لسنة

ملفق لوحدات للتريبية لمنهج ترريبات القوة لوظيف

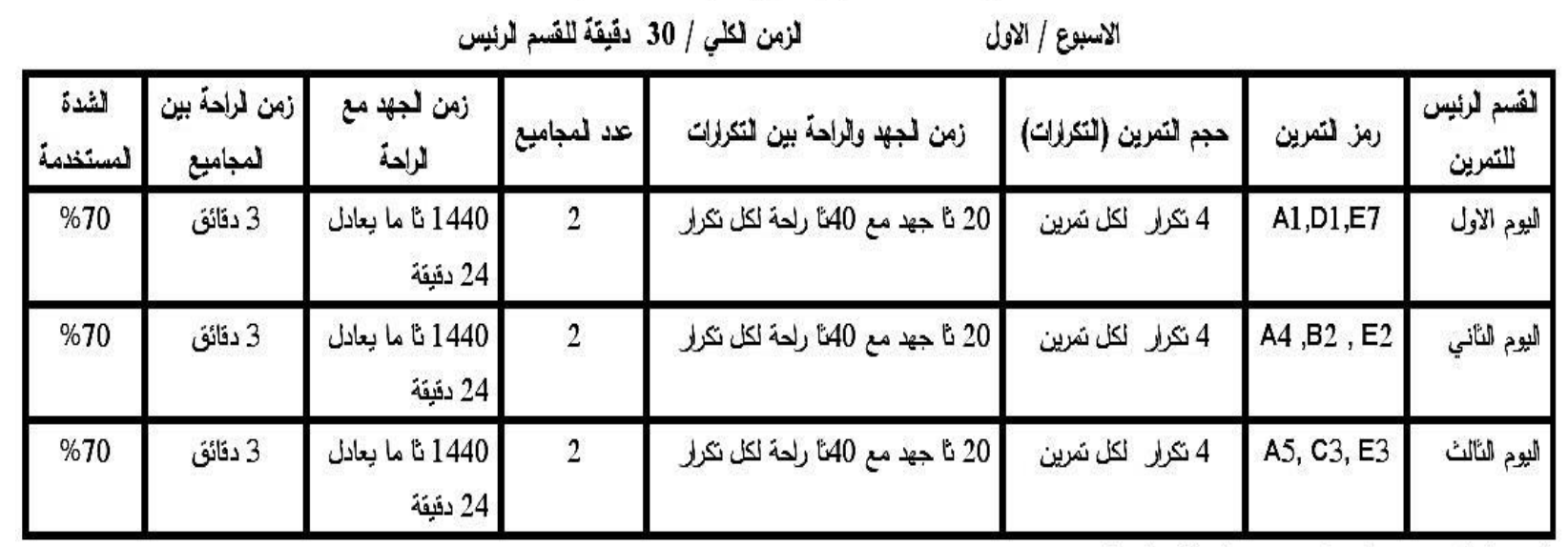

لتاريخ / للمدة هن / / 2015 ولناية / / 2015 